\title{
Pole Changing Wide Speed Range Induction Motor Drive for Electric Vehicles
}

\author{
Rohith \\ Interdisciplinary Center for Energy Research \\ Indian Institute of Science \\ Bangalore, India \\ rohith1@iisc.ac.in
}

\author{
L Umanand \\ Dept. of Electronic Systems Engg. \\ Indian Institute of Science \\ Bangalore, India \\ lums@iisc.ac.in
}

\author{
Subba Reddy B. \\ Dept. of Electrical Engg. \\ Indian Institute of Science \\ Bangalore, India \\ sreddy@iisc.ac.in
}

\begin{abstract}
The paper presents a two phase variable speed induction motor drive for wide speed application. The drive is designed to meet drive cycle requirements of Worldwide harmonized Light vehicles Test Procedure (WLTP). The required torque speed specifications of the induction machine are obtained from the drive cycle. The wide speed range operation of the drive obtained by pole changing technique. The proposed induction motor drive system consists of an online pole changing two phase induction motor which is driven using a four leg voltage source converter. Using the voltage source converter currents are controlled in certain coil groups of the machine to enable operation as two pole and four pole motor. The paper describes the windings configuration and operation of the two phase induction machine drive.
\end{abstract}

Index Terms-Electric Vehicle, Variable speed drives, Induction motor

\section{INTRODUCTION}

The drive systems for electric vehicles require wide speed range operation. In order to reduce the power rating and size of the electric motor and power converter, constant power operation of the electric motor is preferred compared to constant maximum torque operation [1]. Such a drive system also meets the initial acceleration requirement of the vehicle.

Constant power operation in electrical machines is achieved through field weakening. The permanent magnet machines such as permanent magnet synchronous machine(PMSM) and brushless DC machine(BLDC) have higher efficiency and high power to weight or volume ratios compared to induction machines. Field weakening in such machines affects the life and performance of the permanent magnets. As a consequence PM machines have narrow field weakening region [2].

The electric vehicle drive system should have good dynamic performance. The vector controlled induction machines have decoupled torque and field control which are used in electric vehicle drives for good transient performance. The induction machine can be operated for wide speed range constant power mode using field weakening control. The Induction machines have been designed for field weakening up to 3 to 5 times based speed operation in [3]. It has been also shown in [4] for even higher speed range the electronic pole changing the concept for three-phase induction motor can be used [4].

978-1-5386-9316-2/18/\$31.00 @2018 IEEE
In this paper Worldwide harmonized Light vehicles Test Procedure (WLTP) class 3 drive cycle is used to find the mechanical specification of the electric machine. The acceleration requirements of the vehicle are calculated from the drive cycle. Different forces acting on the vehicle for the speed range constituting road load along with the accelerating requirements is used to calculate the torque-speed specifications of the drive. A two to four pole changing two-phase induction motor drive system is proposed for the electric vehicle application. The machine has four sets of windings spread over a phase belt of $180^{\circ}$. The currents in these four windings are controlled to form two pole and four pole rotating magnetic field in the air gap of the machine. The pole changing technique is described using winding functions.

\section{TORQue SPEED SPECIFICATIONS}

The Torque-speed requirement from the electric motor can be calculated from the road load characteristics [5] and drive cycle of the electric vehicles. A first-order non-linear differential equation from [6] gives a basic dynamic model of the electric vehicle.

$$
\begin{aligned}
(M & \left.+J \frac{G^{2}}{\eta_{g} r^{2}}\right) \frac{d v}{d t}=\frac{G T_{m}}{r}-\mu_{r r} m g \\
& -\frac{1}{2} \rho C_{d} A\left(v+v_{0}\right)^{2}-m g \sin (\psi)
\end{aligned}
$$

Where: $M=$ Mass of the vehicle

$J=$ Moment of inertia of the electric motor

$r=$ Wheel radius

$G=$ Gear ratio

$v=$ Vehicle speed $v_{0}=$ Wind speed along the vehicle

$\mu_{r r}=$ Rolling friction coefficient

$g=$ Acceleration due to gravity

$T_{m}=$ Devolped Motor torque

$\rho=$ Air density

$C_{d}=$ Coefficient of aerodynamic drag

$A=$ Frontal area of the vehicle

$\psi=$ grade angle

For calculation of motor mechanical output specifications Worldwide harmonized Light vehicles Test Procedure (WLTP) class 3 drive cycle is used which is shown in Fig. 1. For a 


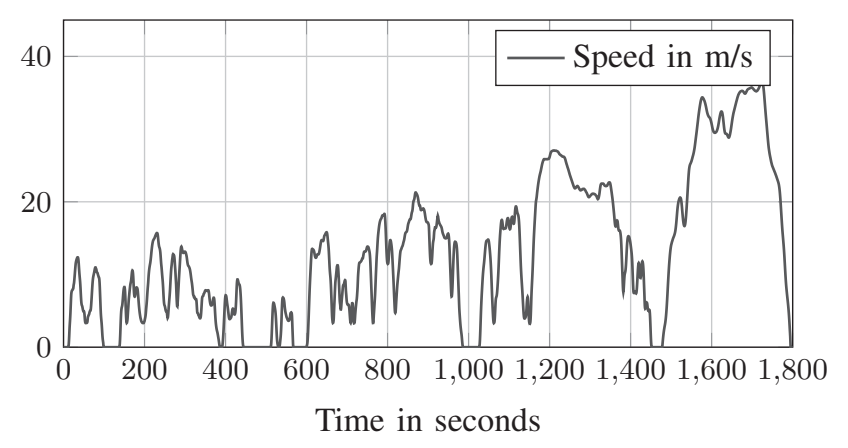

Fig. 1. WLTP Class 3 Drive Cycle

vehicle mass $1400 \mathrm{~kg}$ the dynamic equation along with WLTC drive cycle is used to determine the torque-speed profile of the drive system. The moment of inertia of motor is accounted as $5 \%$ of the mass of the vehicle [6]. The torque-speed characteristics of the drive thus obtained is shown in Fig. 2. From the torque-speed plot, the region of constant torque and constant power can be identified.

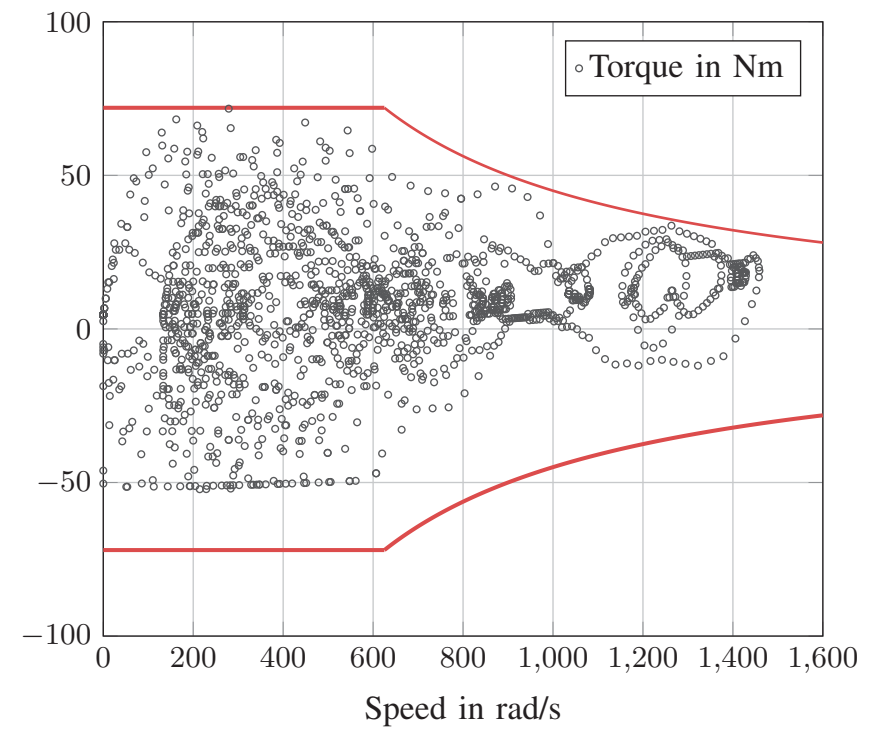

Fig. 2. Torque speed requirements

The constant torque operation at lower speed renders the high starting torque requirement of the vehicle which is required for high initial acceleration. The constant power operation is used for cruising at medium and higher speeds of the vehicle without increasing the power rating of the machine and power converter.

\section{POLE CHANGING INDUCTION MACHINE}

A schematic of stator winding distributions on a 36 slot induction machine stator is shown in Fig. 3. The stator houses fours set of windings would as two-phase four poles. The winding are 1-1', 2-2', 3-3' and 4-4'. Each of these double layered full pitched winding has a phase belt of $180^{\circ}$.
The windings are analyzed using winding functions [7]. The winding functions are the representation of mmf distribution as a function of position in the air gap of the machine for unit current through the winding. The stator winding functions of the two-phase pole changing induction machine are shown in Fig. 4. Two pole and four pole mmf distributions in machine airgap can be obtained by adding or subtracting certain winding functions.

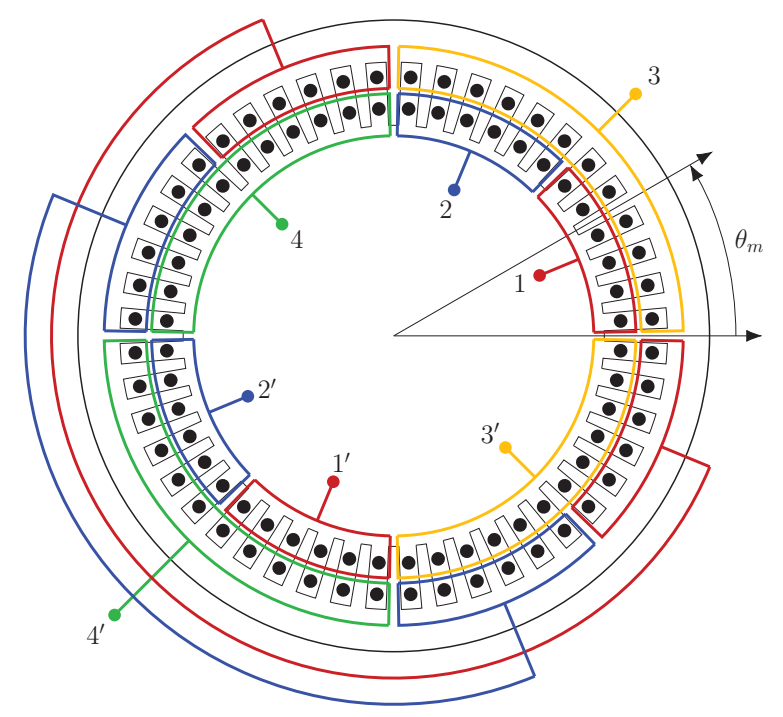

Fig. 3. Winding distribution on 36 slot stator

\section{A. Four Pole Operation}

The four pole mmf distribution can be obtained by adding winding functions as following

$$
\begin{aligned}
& N_{\alpha}^{4}\left(\theta_{r}\right)=N_{1}\left(\theta_{r}\right)+N_{2}\left(\theta_{r}\right) \\
& N_{\beta}^{4}\left(\theta_{r}\right)=N_{3}\left(\theta_{r}\right)+N_{4}\left(\theta_{r}\right)
\end{aligned}
$$

The resultant winding functions for four pole configuration is shown in Fig. 5. The winding functions are displaced by $90^{\circ}$ degrees electrical. Hence by supplying with $90^{\circ}$ phase displaced currents $i_{\alpha}(t)$ and $i_{\beta}(t)$ machine can be made to work as a four pole machine. Thus currents through the coil groups 1-1', 2-2', 3-3' and 4-4' are $i_{1}(t)=i_{\alpha}(t), i_{2}(t)=$ $i_{\alpha}(t), i_{3}(t)=i_{\beta}(t)$ and $i_{4}(t)=i_{\beta}(t)$ respectively for four pole operation.

\section{B. Two Pole Operation}

The two pole mmf distribution can be obtained by subtracting winding functions as following

$$
\begin{aligned}
& N_{\alpha}^{2}\left(\theta_{r}\right)=N_{1}\left(\theta_{r}\right)-N_{2}\left(\theta_{r}\right) \\
& N_{\beta}^{2}\left(\theta_{r}\right)=N_{3}\left(\theta_{r}\right)-N_{4}\left(\theta_{r}\right)
\end{aligned}
$$

Similar to four pole operation, the resultant winding functions for two pole configuration is shown in Fig. 6. Here also the winding functions are displaced by $90^{\circ}$ degrees electrical 

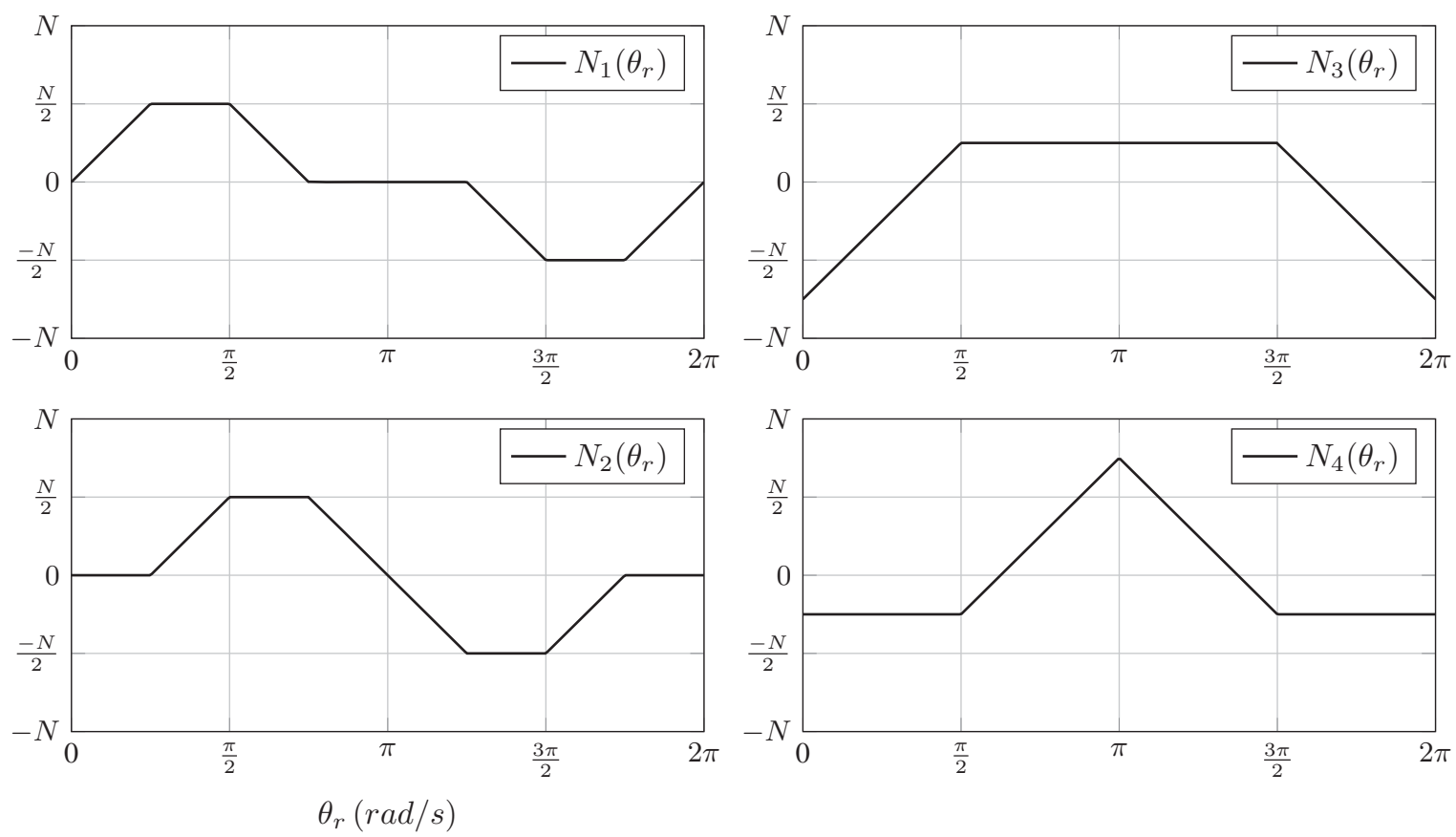

Fig. 4. Winding functions of windings 1-1', 2-2', 3-3' and 4-4'
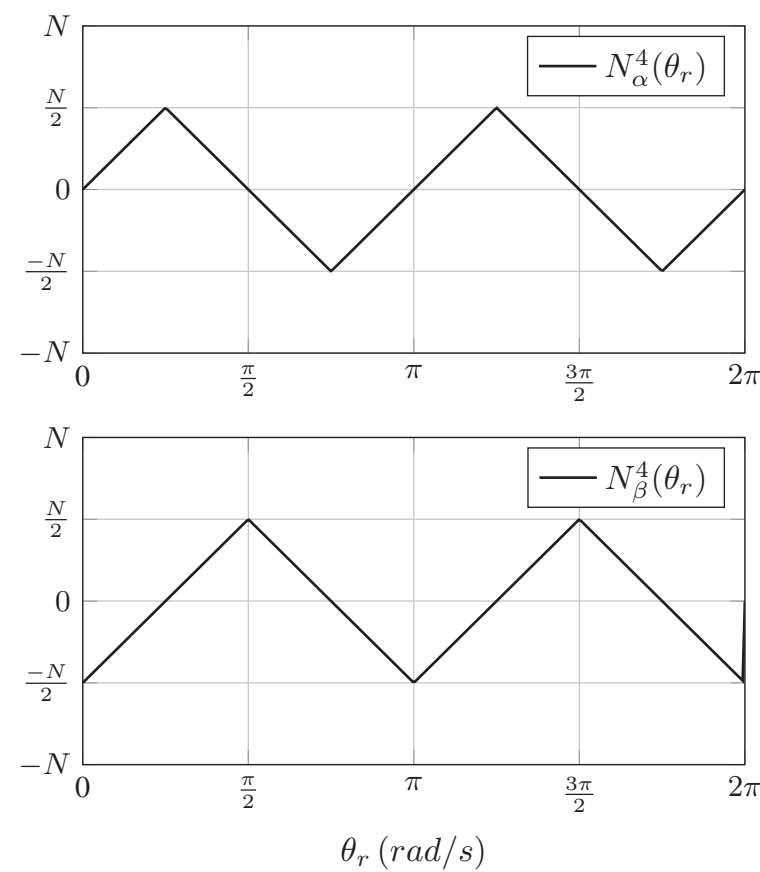

Fig. 5. Winding functions for four pole configuration

forming two pole structure. Hence by supplying with $90^{\circ}$ phase displaced currents $i_{\alpha}(t)$ and $i_{\beta}(t)$ machine can be made to work as a two pole machine. Thus currents through the coil groups 1-1', 2-2', 3-3' and 4-4' are $i_{1}(t)=i_{\alpha}(t)$, $i_{2}(t)=-i_{\alpha}(t), i_{3}(t)=i_{\beta}(t)$ and $i_{4}(t)=-i_{\beta}(t)$ respectively
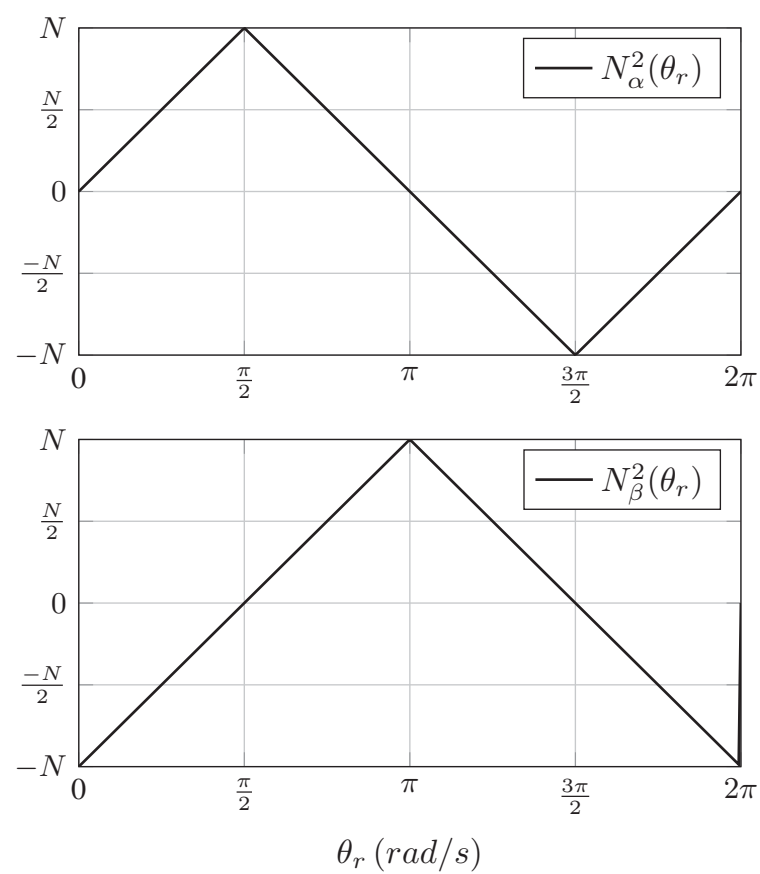

Fig. 6. Winding functions for two pole configuration

for two pole operation. Table I shows the winding currents for different pole operation. 


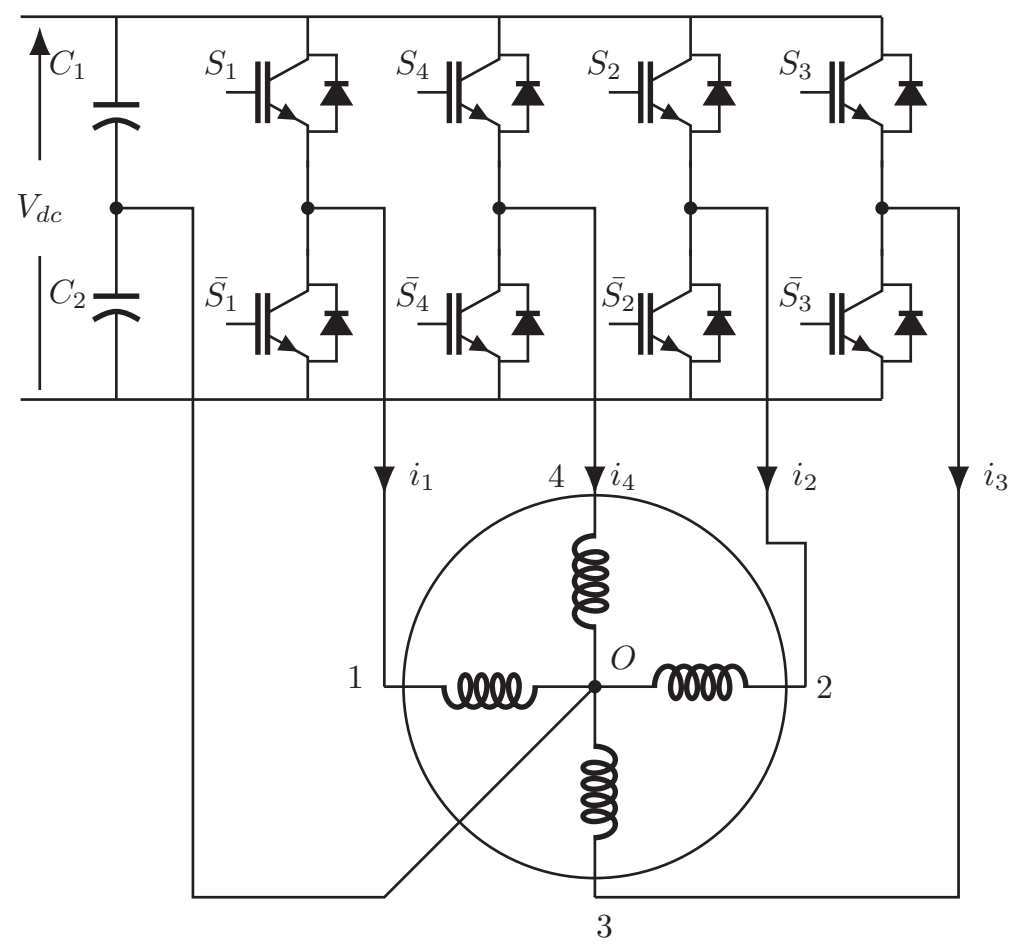

Fig. 7. Drive configuration

\section{INDUCTION MACHINE DRIVE}

A voltage source converter is used to drive the two-phase pole changing drive. By implementing current control in the converter the necessary currents can be injected through the windings for multiple pole operation. The current control of the voltage source converter is used for decoupled torque and field control. As shown in the Fig. 5 four-legged voltage source converter is used to source four winding of the machines. Each winding is to connected to a leg of the inverter and the neutral point is connected to the midpoint of capacitors as shown in Fig. 5. Hence every coil currents can be independently controlled to the desired value. The pole changing can be implemented by injecting currents to winding as shown in Table I.

The neutral current during four pole operation is not zero as the four winding currents will not add upto to zero. Hence capacitor voltage will have ripple in fundamental frequency. But in case of two pole operation the neutral current will be zero as the sum of individual winding currents is zero.

\section{RESULTS}

Simulation of the proposed drive was perfomed using MATLAB/Simulink. Detailed switching model of the drive was used to study the steady state as well as dynamic performance of the pole changing drive. The converter switches were switched at a frequency of $20 \mathrm{kHz}$. The results of four pole and two pole operation are discussed below.
TABLE I

WINDING CURRENTS FOR DIFFERENT POLE CONFIGURATIONS

\begin{tabular}{|c|c|c|}
\hline Winding Currents & Four Pole & Two Pole \\
\hline$i_{1}(t)$ & $i_{\alpha}(t)$ & $i_{\alpha}(t)$ \\
\hline$i_{2}(t)$ & $i_{\alpha}(t)$ & $-i_{\alpha}(t)$ \\
\hline$i_{3}(t)$ & $i_{\beta}(t)$ & $i_{\beta}(t)$ \\
\hline$i_{4}(t)$ & $i_{\beta}(t)$ & $-i_{\alpha}(t)$ \\
\hline
\end{tabular}

\section{A. Four Pole Operation}

Simulation results for four pole operation is shown in Fig. 8.The machine is made to accelarate from $1000 \mathrm{rpm}$ to 1500 $\mathrm{rpm}$ at time $\mathrm{t}=1$ second. The indvidual winding currents $i_{1}(t)$, $i_{2}(t)$ and $i_{3}(t)$ and $i_{4}(t)$ are also shown in Fig. 8.

\section{B. Two Pole Operation}

For two pole operation of the machine the results of the simulation are shown in Fig. 9. Here also the machine the is accelarated from $3500 \mathrm{rpm}$ to $4000 \mathrm{rpm}$. The indvidual winding currents $i_{1}(t), i_{2}(t)$ and $i_{3}(t)$ and $i_{4}(t)$ are shown in Fig. 9.

\section{CONCLUSION}

The paper proposes a low switch count wide speed range induction motor drive for electric vehicle application. Only 

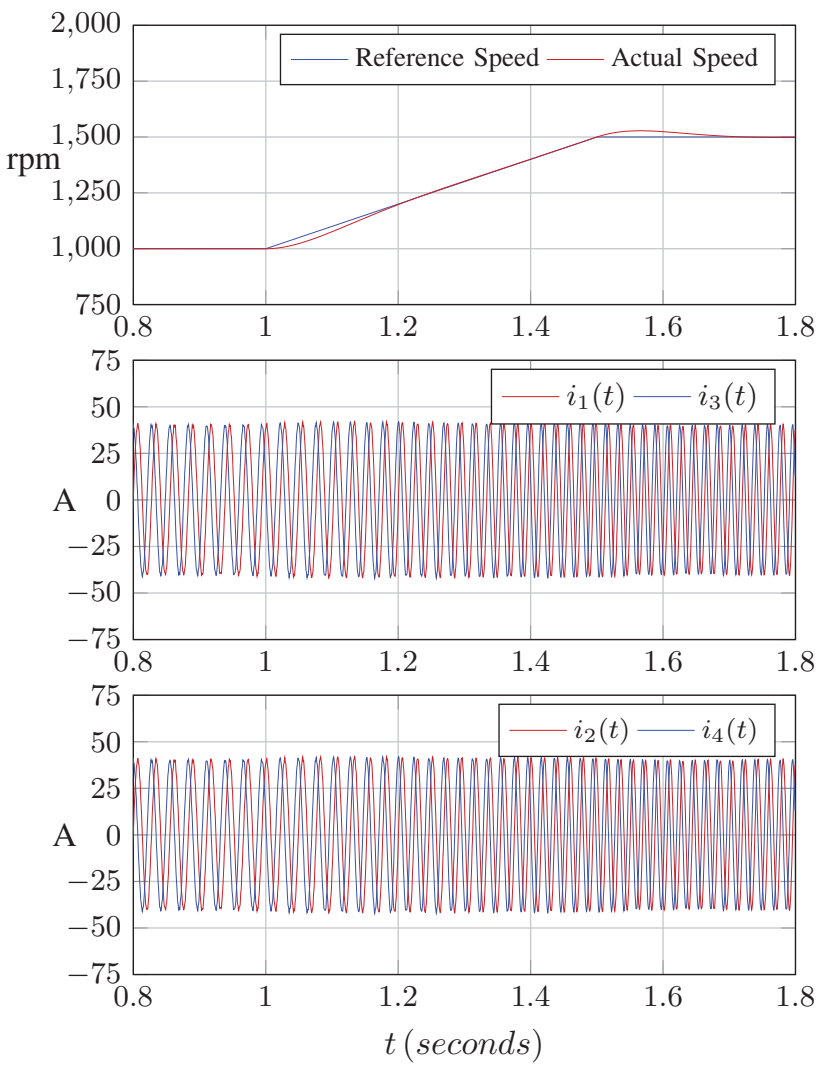

Fig. 8. Four Pole Operation

the connections of a two phase four pole machine windings are taken out for pole change operation. However, compared to standard two phase drives this drives requires additional switches for operational and control.

\section{ACKNOWLEDGEMENT}

This research is based upon work supported by the Department of Science and Technology (DST), India, for the project entitled "UK India Clean Energy Research Institute (UKICERI)" (Sanction No. DST/RCUK/JVCCE/2015/02).

\section{REFERENCES}

[1] R. Vandana and B. G. Fernandes, "Optimal sizing of motor - battery system for in wheel electric vehicles," in IECON 2010 - 36th Annual Conference on IEEE Industrial Electronics Society, Nov 2010, pp. 2510 2515.

[2] M. Ehsani, Y. Gao, and J. M. Miller, "Hybrid electric vehicles: Architecture and motor drives," Proceedings of the IEEE, vol. 95, no. 4, pp. 719-728, April 2007.

[3] A. BOGLIETTI, P. FERRARIS, M. LAZZARI, and F. PROFUMO, "A new design criteria for spindles induction motors controlled by field oriented technique," Electric Machines \& Power Systems, vol. 21, no. 2, pp. 171-182, 1993.

[4] M. Osama and T. A. Lipo, "Modeling and analysis of a wide-speedrange induction motor drive based on electronic pole changing," IEEE Transactions on Industry Applications, vol. 33, no. 5, pp. 1177-1184, Sep 1997.

[5] M. Ehsani, K. M. Rahman, and H. A. Toliyat, "Propulsion system design of electric and hybrid vehicles," IEEE Transactions on Industrial Electronics, vol. 44, no. 1, pp. 19-27, Feb 1997.
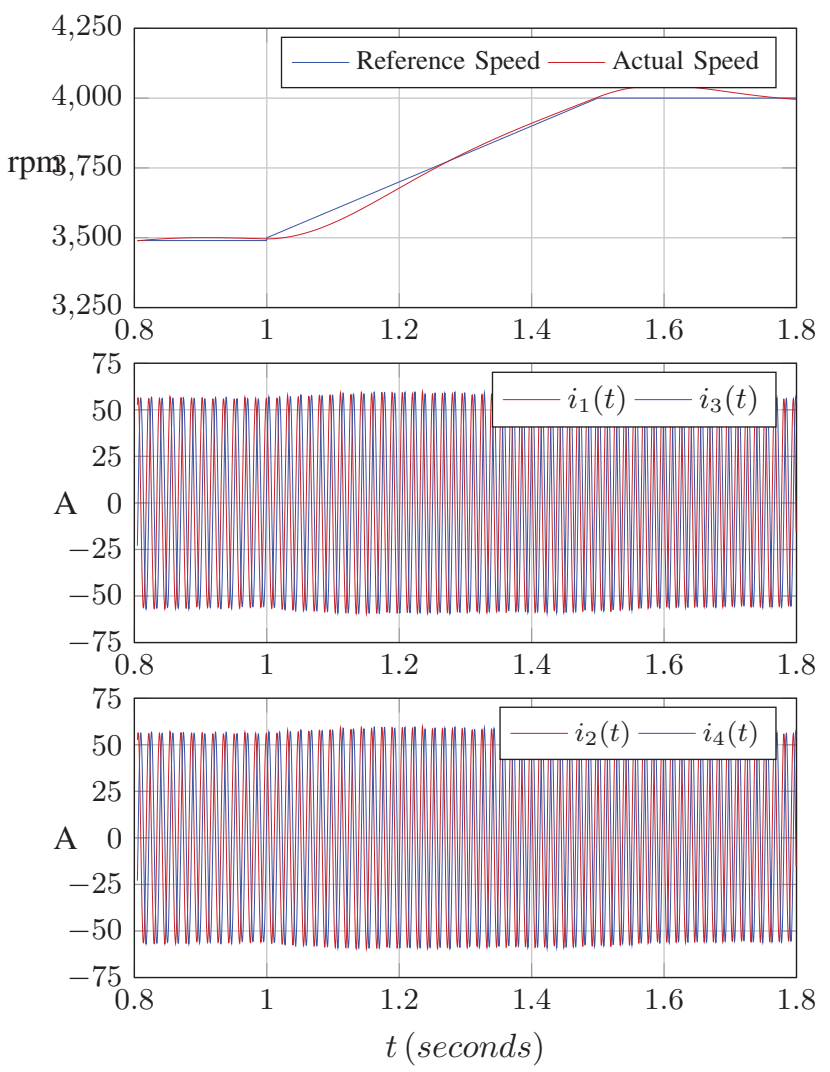

Fig. 9. Two Pole Operation

[6] J. Larminie and J. Lowry, "Electric vehicle technology explained," 01 2003.

[7] S. M. Raziee, O. Misir, and B. Ponick, "Winding function approach for winding analysis," IEEE Transactions on Magnetics, vol. 53, no. 10, pp. $1-9$, Oct 2017. 